\title{
The Lived Experience of First-Episode Psychosis: A Systematic Review and Metasynthesis of Qualitative Studies
}

\author{
Amelie Noiriel $^{\mathrm{a}}$ Laurence Verneuil $^{\mathrm{b}}$ Ingrid Osmond ${ }^{\mathrm{c}}$ Emilie Manolios $^{\mathrm{b}, \mathrm{d}}$ \\ Anne Revah-Levy ${ }^{b, c}$ Jordan Sibeoni ${ }^{b, c}$ \\ aESMPI, Groupe MGEN, Paris, France; ${ }^{b}$ ECSTRA Team, UMR-1153, Inserm, Université de Paris, Paris, France; ' Service \\ Universitaire de Psychiatrie de l'Adolescent, Argenteuil Hospital Centre, Argenteuil, France; d Service de Psychologie \\ et Psychiatrie de Liaison et d'Urgences, Hôpital Européen Georges Pompidou AP-HP, Hôpitaux Universitaires Paris \\ Ouest, Paris, France
}

\section{Keywords}

First-episode psychosis · Qualitative research · Lived experience $\cdot$ Patient-centered approach

\begin{abstract}
Both research and care have focused on first episodes of psychosis (FEPs) as a way to address the issue of early stages of schizophrenia and to reduce the duration of untreated psychosis. The objective of this study was to explore specifically the lived experience of FEP from the point of view of patients and their families by applying a metasynthetic approach, including a systematic review of the literature and analyses of qualitative studies on the subject. This metasynthesis follows thematic synthesis procedures. Four databases were systematically searched for qualitative studies reporting FEP from the patient or family's perspective. Article quality was assessed with the Critical Appraisal Skills Program. Thematic analysis was used to identify key themes and synthesize them. Thirty-eight articles were included, covering data from 554 participants (378 patients and 176 relatives). Three themes emerged from the analyses: (1) When and how does a FEP start? (2) What are its negative and positive aspects? (3) How do patients and families recount FEPs? Our results found important discrepancies between the experiences of
\end{abstract}

karger@karger.com

(c) 2020 S. Karger AG, Basel

www.karger.com/psp

Karger! patients and those of their families, especially regarding positive aspects. In light of the confusion reported by patients and notable in our results, we also discuss the gap between the name, FEP, and the lived experience of patients and family members in order to explore its practical implications.

(c) 2020 S. Karger AG, Basel

\section{Introduction}

Interest in the prodromal and early stages of schizophrenia has grown in recent years, in both clinical practice and research. The primary focus is on reducing the duration of untreated psychosis and improving disease prognosis [1]. In this context, both research and care have focused specifically in recent years on first episodes of psychosis (FEPs).

These episodes have thus been the object of numerous studies: epidemiologic [1], with an incidence estimated at 33.3 per 100,000 per year [2]; biological, for example, blood cortisol levels [3] and biomarkers [4]; morphological [5], concerning especially the hippocampus [6]; and genetic [7] with, in particular, correlations between the

\section{A.R.-L. and J.S. contributed equally to this work.}


polygenic risk score and clinical or prognostic aspects of the FEP $[8,9]$.

The social, clinical, and neurocognitive characteristics have also been examined in detail $[10,11]$, especially to explore the factors predictive of treatment resistance during FEPs, including negative symptoms, comorbid substance use, and "lower premorbid functioning" [12].

Numerous clinical trials [13-15] have tested treatments (pharmaceutical treatment, psychotherapy, physical activity) for FEP, as well as departments or clinics specifically for FEP or early intervention programs. The latter have demonstrated their superiority over standard treatment in terms of effectiveness of care [16] and reduction of mortality $[2,17]$.

To a lesser extent, FEPs have also been the object of qualitative studies examining how patients and their families and friends recount and understand this experience. Conducting qualitative research is becoming essential in psychiatry in general and among patients experiencing FEP in particular. The past decade in psychiatry has been characterized by movement from a doctor-centered to a patient-centered approach to treatment outcomes, illustrated by the development of the recovery model $[18,19]$, patients' empowerment [20], shared decision-making [21], and more globally patient and public involvement [22] in the field. Nowadays, psychiatrists must try to see each patient's mental illness through the eyes of the patient and the family in order to integrate patients' preferences, choices, and needs into the decision-making process. This shift in the patient's role in care requires psychiatry to move beyond its traditional biomedical model and paternalistic approach, to take the patient's subjectivity into account, and to place the patient's lived experience at the center of the care process. Qualitative methods fit this societal evolution in psychiatry well, aiming as they do to describe and capture the lived experience in great depth. They are especially useful in the context of FEP, which is often the first encounter with psychiatry and the beginning of a - potentially long - therapeutic journey. Their analysis can produce concrete ideas directly based on patients' lived experience that can improve patients' adherence to care and their therapeutic alliances [21].

Because qualitative studies are usually conducted with small samples and in specific contexts, there may often be concerns about the generalizability of their results. The WHO has recently affirmed the importance of synthesizing data from qualitative studies to help in the development of health policies and clinical practices [23]. Metasynthesis is a method that not only synthesizes the exist- ing data but also analyzes them transversally to produce new knowledge [24, 25]. This method is ideal for reaching wider audiences, for it makes qualitative research more accessible and generates hypotheses that can be tested. It can also enable qualitative research to influence guidelines and inform health policies. This was the case for instance for the NICE guidelines for asthma [26] and diabetes in pregnancy [27].

We have found 3 systematic reviews of qualitative studies concerning FEPs. The descriptive review by Boydell et al. [28] of 31 articles (reporting 27 studies) included the perspectives of patients, families, and healthcare professionals; it simultaneously examined studies exploring the prodromal phase. Their results focused on "the complex social processes of achieving identity, acquiring perspectives, doing activity and developing relationships as experienced by young people who have experienced psychosis and their significant others." They emphasized the central role of social relations during the prodromal phase, directly associated with a high degree of distress and functional disability, and argued for further qualitative research to explore the intersubjective, social, and cultural aspects of early psychosis programs. Griffiths et al. [29] conducted a metasynthesis focused on distress during the FEP. They analyzed 33 studies considering only patients' perspectives and distinguished 2 forms of distress: intrapersonal and interpersonal. The sources of distress were multiple and substantially different from those routinely recognized and targeted in clinical practice. This led the authors to highlight the importance of being service userled when delivering mental healthcare. Jordan et al. [30] systematically reviewed the literature on the positive changes experienced after a FEP. This review included 40 articles, 37 of them qualitative studies, and found numerous positive aspects reported by patients and their families and close friends: individual, relational, and spiritual. At the individual level, they found that patients experienced changes in lifestyle and personality (e.g., more insight and more clarity). At the relational level, FEP led to improved, closer family bonds. FEP also changed service users' and family members' sense of their role in society, for example, by becoming willing to engage in peer-support actions. At the spiritual level, the few studies addressing this aspect found that prayer or attending religious services were helpful in facilitating positive change.

These reviews either focus on specific aspects or cover other experiences. To our knowledge, no review of qualitative studies has specifically explored the lived experience of individuals with an FEP from their own points of view of and those of their families. 
Table 1. Search strategy for each database

Medline (PubMed) (1948-)

((“qualitative research” [Mesh] OR "Nursing Methodology Research” [Mesh] OR "Focus Groups” [Mesh] OR "observation" [Mesh] OR "qualitative research" OR "qualitative study" OR "qualitative method") AND (perception OR attitude OR feeling OR knowledge OR belief OR view OR perspective OR opinion OR experience OR image OR "self-concept" OR barrier* OR psycholog* OR management OR organization* OR “Attitude of Health Personnel"[Mesh] OR “Attitude to Health"[Mesh] OR "Knowledge"[Mesh] OR "Psychology”[Mesh] OR "Self Concept”[Mesh] OR "Health Services Administration”[Mesh]) AND ("psychotic disorder" [Mesh] OR "schizophrenia” [Mesh] OR “psychosis” OR "psychotic disorder*” OR "schizophrenia”) AND ("Adolescent” [Mesh] OR "Young Adult” [Mesh] OR "early” OR "first episode” OR "adolescence” OR “adolescent” OR “adolescents" OR “young” OR “youth”))

PsycINFO (EBSCO Publishing) (1800-)

(DE “Qualitative Research” OR DE “Interviews” OR DE “Intake Interview” OR DE “Interview Schedules” OR DE "Psycho diagnostic Interview” OR DE “Grounded Theory” OR DE “Observation Methods” OR DE "Ethnography” OR DE "Discourse Analysis” OR DE “Content Analysis” OR DE "Phenomenology” OR DE "Philosophies” OR DE “Constructivism” OR DE "Hermeneutics” OR DE “Narratives” OR DE "Biography” OR DE "Life Review" OR DE "Storytelling” OR "qualitative research" OR "qualitative study" OR "qualitative method" OR "qualitative research" OR "qualitative study" OR “qualitative method”) AND (DE “Attitudes” OR DE “Knowledge (General)” OR DE “Psychology” OR DE “Management” OR psycholog* OR feeling OR attitude OR knowledge OR view OR perspective OR opinion OR experience OR image OR "self-concept" OR barriers OR management OR organization*) AND (DE "Psychosis" OR DE “Acute Psychosis") AND (DE "Schizophrenia” OR DE "Paranoid Schizophrenia” OR DE “Acute Schizophrenia” OR "psychotic disorder” OR “schizophrenia”) AND (DE “Adolescent Psychiatry” OR DE “Adolescent Psychology” OR DE “Adolescent Psychopathology” OR DE “Adolescent Psychotherapy+” OR DE “Adolescent Attitudes” OR DE “Adolescent Development” OR “teenagers” OR “teens” OR “adolescence” OR “adolescent” OR “adolescents” OR "young” OR "youth" OR "young adult" OR "early" OR "first episode”)

Limits: Humans, Journal Articles

CINAHL Plus - Cumulative Index to Nursing and Allied Health Literature (EBSCO Publishing) (1981-) ((MH “Qualitative Studies+”) OR (MH “Focus Groups”) OR (MH “Interviews+”) OR (MH "Narratives”) OR (MH “Observational Methods+”) OR (MH “Discourse Analysis”) OR (MH “Thematic Analysis”) OR (MH "Semantic Analysis") OR (MH "Field Studies") OR (MH “Audio recording”) OR (MH “Constant Comparative Method”) OR (MH “Content Analysis”) OR (MH “Field Notes”) OR (“qualitative research”) OR ("qualitative study") OR ("qualitative method”)) AND ((MH “Attitude+") OR (MH “Knowledge+") OR (MH "SelfConcept+") OR (MH "Psychology+") OR (MH "Management+") OR ("feeling”) OR ("attitude”) OR ("knowledge”) OR ("view”) OR ("perspective”) OR (“opinion”) OR (“experience”) OR ("image”) OR ("selfconcept”) OR (“barriers”) OR (“management”) OR (“organization*”) OR (“psycholog*”) AND ((MH "psychotic disorders") OR (MH” schizophrenia”) OR ("psychosis”) OR (“schizophrenia”)) AND ((MH “Adolescence+") OR (MH “Adolescent Care”) OR (MH “Adolescent Health”) OR (MH “Adolescent Psychiatry”) OR (MH “Adolescent Psychology”) OR (MH “Adolescent Development”) OR (MH “Adolescent Behavior”) OR (“teenagers”) OR (“teens”) OR (“adolescence”) OR (“adolescent”) OR (“adolescents”) OR (“young") OR (“first episode") OR (“early") OR ("young adult"))

Limits: Humans, Journal Articles

SSCI - Social Sciences Citation Index (Web of Science) (1956-)

("case study" OR "constant comparative" OR "content analysis" OR “descriptive study" OR "discourse analysis" OR (ethnography OR ethnographic) OR ("Focus group” OR "focus groups”) OR "grounded theory” OR interview* OR narrative* OR observation* OR "qualitative method*” OR "qualitative research" OR "qualitative study" OR "thematic analysis" OR "semi-structured” OR “in depth") AND (perception OR attitude OR feeling OR knowledge OR belief OR view OR perspective OR opinion OR experience OR image OR "selfconcept" OR barrier* OR psycholog* OR management OR organization*) AND ( "first episode psychosis" OR "psychosis" OR "schizophrenia" OR “psychotic disorders") AND ( "first episode" OR "teenagers" OR "teens" OR “adolescence” OR “adolescent” OR “adolescents” OR “young” OR “early” OR "young adult” OR "adolescent psychiatry” OR "adolescent psychology”)

Limits: Humans, Articles

The Lived Experience of First-Episode Psychosis
Psychopathology 2020;53:223-238

DOI: $10.1159 / 000510865$ 
Table 2. Studies' contribution for each theme

\begin{tabular}{lll}
\hline Theme of the results & $\begin{array}{l}\text { Highest CASP score studies } \\
(17 / 20 \text { or higher })\end{array}$ & $\begin{array}{l}\text { Lowest CASP score } \\
\text { quartile }(14 / 20,15 / 20,16 / 20)\end{array}$ \\
\hline $\begin{array}{l}\text { (1) When and how does a FEP start? } \\
\text { A sudden beginning, a break? }\end{array}$ & {$[34,36,38,44-52]$} & {$[53]$} \\
$\begin{array}{l}\text { Not a beginning but a continuation? } \\
{[39,42,50,54]}\end{array}$ & {$[37,55,56]$} \\
\hline $\begin{array}{l}\text { (2) What are its negative and positive aspects? } \\
\text { A painful experience of distress }\end{array}$ & {$[36,40-42,45,46,48,50-52,57-61]$} & {$[37,62-64]$} \\
A positive experience & {$[41,42,44,45,50,54,57,58,60,65-67]$} & {$[55,62]$} \\
\hline $\begin{array}{l}\text { (3) How do patients and families recount it? } \\
\text { The difficulty of putting it into words }\end{array}$ & {$[33,36,39,43,45,48,50,68,69]$} & {$[72]$} \\
Making sense of what has been experienced? & {$[40,45,58,70,71]$} & {$[37$} \\
\hline
\end{tabular}

Our objective was to fill this gap by applying a metasynthetic approach to synthesize the qualitative literature on the subject to generate new insights into FEPs that can better inform future health policies.

\section{Methods}

\section{Study Design}

This metasynthesis relies on our 6-stage approach inspired by the model of meta-ethnography and the procedures of thematic synthesis [25]. It follows the ENTREQ reporting guidelines. Our research group has already used this approach in other studies [3132].

Our approach comprised 6 successive stages:

1. Defining the research question, the subjects, and the types of studies to be included

2. Identifying and selecting the studies

3. Assessing the quality of the studies selected

4. Analyzing the studies, identifying their themes, and translating these themes across each study

5. Generating the themes of the analysis and structuring the synthesis

6. Writing the synthesis.

The thematic analysis contains 2 phases: one descriptive, which defines and compares the themes, and the other interpretive; it develops original ideas drawn from the review.

\section{Search Strategy and Selection Criteria}

We conducted a systematic search in 4 databases according to a search algorithm specific to each base: Medline, PsycINFO, EMBASE, and SSCI through May 2019.

Preliminary research identified several articles from which we selected key words. The research group used existing literature reviews to determine a list of key words, a mix of free-text terms and thesaurus terms, referring to FEP and qualitative research, to collect studies indexed in the databases. Our search strategy is detailed in Table 1.
Studies met the inclusion criteria if they were qualitative articles about FEP from the perspective of patients or their family members, published in peer-reviewed journals, in either English or French. The exclusion criteria rejected quantitative or mixed studies, reviews, commentaries, editorials, dissertations and theses, and non-peer-reviewed journal articles. Articles dealing specifically with the experience of care for FEP were excluded from this review because we plan to conduct another metasynthesis of that specific topic. We discussed potential articles at meetings of our research group, composed of specialists in qualitative research and psychiatrists (who treat children, adolescents, and adults).

Extensive lateral searches - systematic checking of reference lists, hand searching of key journals and the PubMed sidebar of related articles - also sought to identify papers that might have eluded our algorithms. Three authors (A.N., J.S., and I.O.) independently screened the papers retrieved, initially by title, then by abstract, and finally by full text.

After collecting the references and eliminating duplicates, 3 authors (A.N., L.V., and J.S.) subsequently read the titles and abstracts to assess their relevance to our topic and methodology. The database indexing of qualitative studies was rather poor, and most of the references collected turned out to be quantitative studies. They were eliminated at this step.

The potentially relevant articles were then read in full, and a second selection kept only the articles that met our inclusion criteria. Disagreements were resolved during group meetings. The agreement level at these meetings was high. In fact, there were no disagreements regarding either participants or methods. We included only studies with a qualitative design, that is, based on a well-known qualitative methodology (phenomenology, grounded theory, thematic analysis, etc.), using specific data collection tools (individual or group interviews, observation, written documents), and a qualitative analysis approach, as shown by the presentation of the results (i.e., thematic organization). Disagreements initially occurred regarding the topic, as we had planned to include all studies related to the experience of FEP without requiring that it necessarily be the principal object of the study. To better operationalize this criterion and avoid further disagreements, we decided to include an article if at least one paragraph of the results concerned the lived experience of FEP. 
Table 3. Process of thematic analysis

\begin{tabular}{|c|c|c|}
\hline & Activities & Rationale \\
\hline Stage 1 & Repeatedly read each summary, as a whole & Obtain a global picture of the results of the study \\
\hline Stage 2 & Code the summary by making descriptive notes & Make descriptive notes grounded in the study results \\
\hline Stage 3 & $\begin{array}{l}\text { Make conceptual notes through processes of condensation, } \\
\text { abstraction, and comparison of the initial notes }\end{array}$ & $\begin{array}{l}\text { Categorize initial notes and reach a higher level of } \\
\text { abstraction }\end{array}$ \\
\hline Stage 4 & Identify initial themes & $\begin{array}{l}\text { Themes are labels that summarize the essence of a } \\
\text { number of related conceptual notes }\end{array}$ \\
\hline Stage 5 & $\begin{array}{l}\text { Identify recurrent themes across studies' summaries and produce } \\
\text { a coherent ordered table of the themes and sub-themes }\end{array}$ & $\begin{array}{l}\text { During this more analytic stage, researchers try to make } \\
\text { sense of the associations between the themes found }\end{array}$ \\
\hline
\end{tabular}

Assessment of Article Quality

We assessed the quality of included articles with the Critical Appraisal Skills Program (CASP) [33], a 10-item tool with 2 screening questions about the research aims and appropriate use of a qualitative methodology and 8 questions covering research design, sampling strategy, data collection, researcher's reflexivity, ethical issues, data analysis, the findings, and the value of the research. It has 3 possible responses for each question: yes (2 points), partially ( 1 point), and no ( 0 points). The maximum score for each article is thus 20. Two authors (J.S. and A.N.) performed this assessment independently and then discussed the results within the research group until they reached agreement. Given the lack of consensus about the role and function of study quality assessment as part of systematic reviews, we did not exclude any study from the analysis based on our evaluation. The quality of the studies was high: the lowest score was $14 / 20$, and $80 \%$ of the studies (31 studies) received a score of $17 / 20$ or higher. Table 2 details the contribution of the studies to each theme. It shows that none of our results relied only on lower-quality studies.

\section{Data Analysis}

Our analysis began with an attentive reading and then repeated readings of the titles, abstracts, and texts of each article. Three researchers (A.N., I.O., and E.M.) extracted the formal characteristics of the studies, and 3 (A.N., J.S., and A.R.-L.) independently extracted and analyzed the first-order results (i.e., the study results) and the second-order results (authors' interpretations and discussions of the results) in the form of a summary for each study selected; these independent analyses were then compared and discussed at the research meetings.

Thematic analysis followed the 5-stage approach (Table 3) and enabled us to develop themes inductively from our study data. The work of translation involved comparing and assembling the themes obtained by the analysis of each article to retain the key themes that capture similar ideas in the different articles and then to develop overarching concepts about the research question. The high level of rigor of the results was obtained by triangulation of both the data sources and the analyses: 3 independent analyses and monthly research meetings to discuss the results. NVivo 12 software was used to manage data, facilitate the development of themes, and verify the researchers' contributions to the findings.

The Lived Experience of First-Episode Psychosis

\section{Reflexivity}

Addressing reflexivity issues was made possible by working together as a group. Members of our research group each brought a particular angle to the discussions. The first author is a junior psychiatrist working in an adult psychiatry department; the last 2 authors are senior psychiatrists, one a professor of child and adolescent psychiatry, and the other a child and adolescent psychiatrist specialized in adolescent psychiatry. Within the research group, the first author voiced more concerns about the future life and possibilities of the patient after a FEP, whereas the last 2 authors were more focused on how this adverse experience directly impacts the youth's development. To avoid being confined to the sole perspectives of psychiatrists, we asked a psychologist and a medical doctor who was not a psychiatrist to join the research group. The psychologist helped us develop a more global point of view that was not only medical and that also paid more attention to the experiences of family members. The medical doctor had more distance with the topic and a more theoretical approach that enabled the research group to discuss epistemological and nosographic aspects.

\section{Results}

\section{Presentation of the Studies}

We collected 2,530 references, that is, 2,221 after eliminating duplicates. After a first evaluation based only on titles and summaries, we eliminated 2,044 references, then read the remaining 177 articles, and determined that 38 of them met our inclusion criteria, that is, $1.5 \%$ of the initial 2,530 articles (Fig. 1). This percentage is consistent with that reported by other metasyntheses [31, 32].

The 38 studies included a total of 554 participants. In all, 378 patients were questioned and 176 family members. ${ }^{1}$ Only 9 studies (or about one quarter) included, in

\footnotetext{
1 The total of men and women does not equal the total number of participants, because several studies did not report the sex of their participants.
} 
Fig. 1. PRISMA diagram depicting the flow

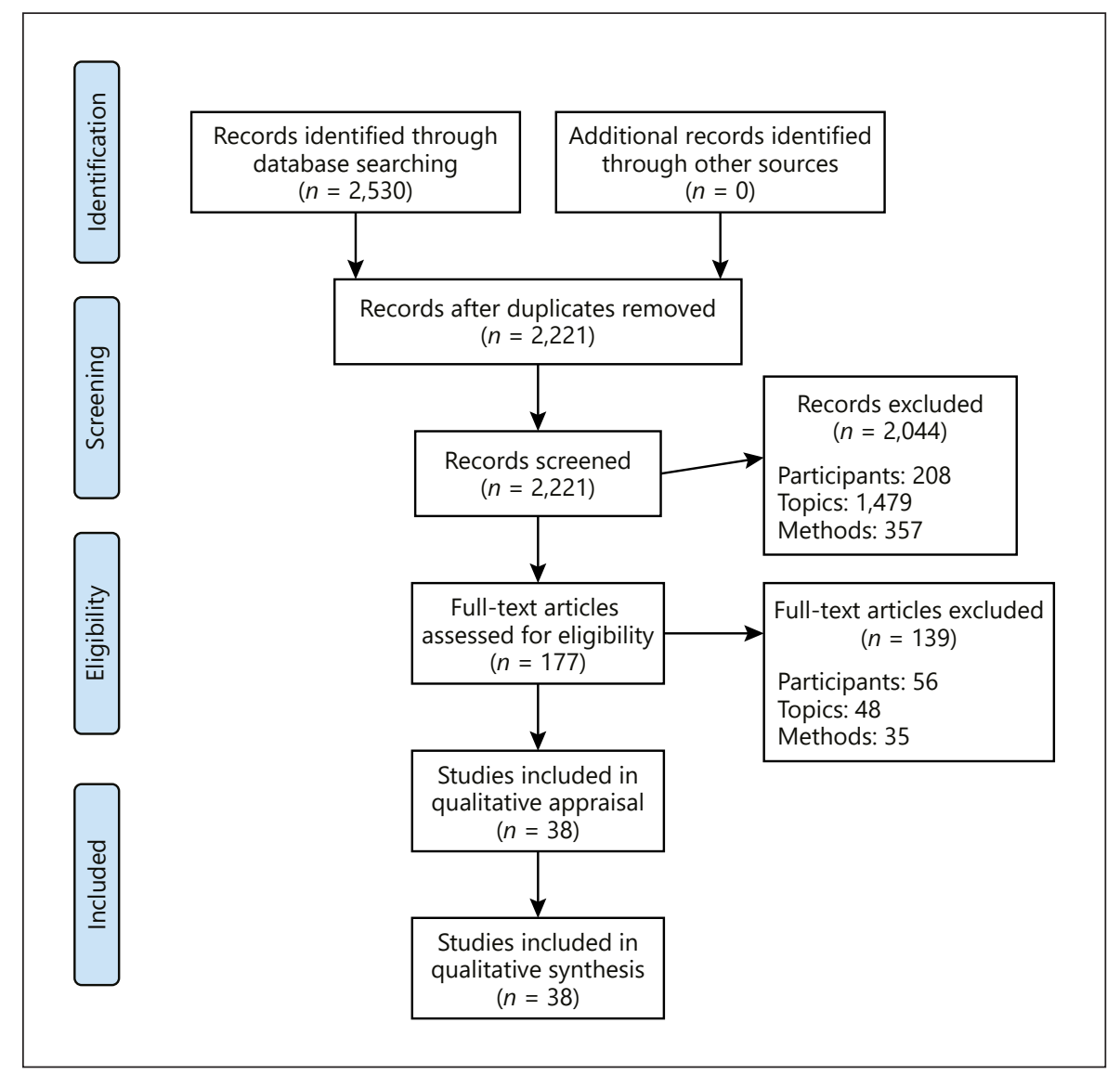
es of the study selection.

part or only, hospitalized participants or their family and friends [34-41]. The other studies concerned only patients (or their families or close friends) who were managed as outpatients and were stabilized; an acute episode was an exclusion criterion in most studies.

Table 4 describes the studies' principal characteristics.

\section{Quality Evaluation}

The overall quality of the articles, assessed according to the CASP criteria, was good. All of the articles had a score of $14 / 20$ or higher. The point most frequently absent from the authors' methodology sections was reflexivity, that is, a critical examination of the role played by the authors through all stages of the research process. The absence of reflexivity can impede an understanding of the process by which the researchers develop the study and interpret their results. One potential explanation for the failure to mention it may be the editorial constraints of scientific journals, which limit the number of words or characters. Seven studies obtained a score of 20/20 [35, 42-47]. Secondary analysis with the 10 studies with the lowest quality according to CASP did not change the results. Table 2 gives a list of which original studies contributed to which themes.

\section{Thematic Analysis}

Three themes emerged from the analyses: (1) When and how does a FEP start? (2) What are its negative and positive aspects? and (3) How do patients and families recount FEPs? Table 5 presents quotations from participants and from the authors of the primary studies for each theme. Figure 2 presents an overview of the results.

\section{When and How Does a FEP Start?}

\section{A Sudden Beginning, a Break?}

For the families, their loved one's FEP began abruptly. They reported a moment of crisis that instigated their help-seeking. The crisis was sometimes manifested by violent or dangerous behavior by the individual $[38,45]$ or by immediately life-threatening suicidal behavior $[34,36$, 


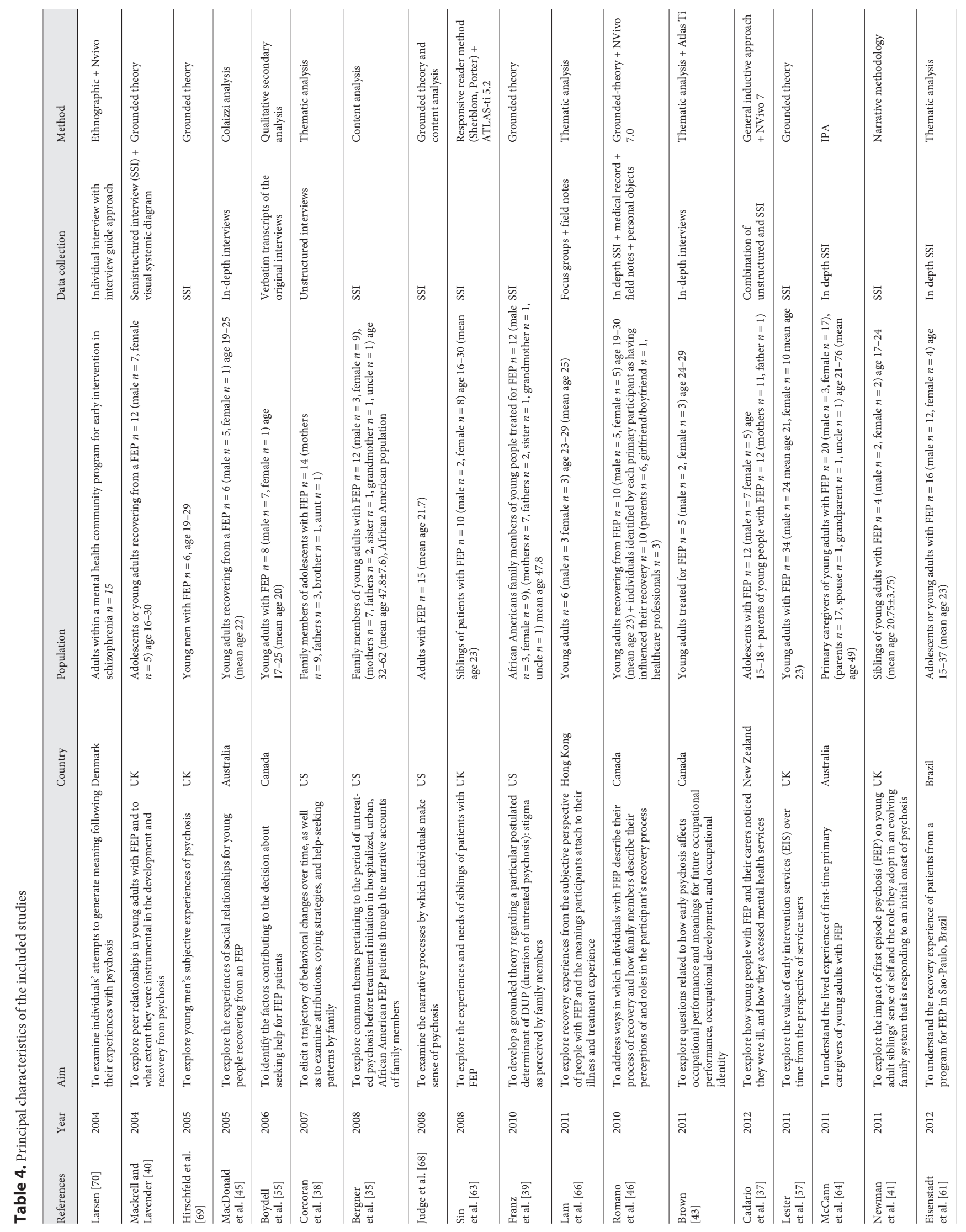




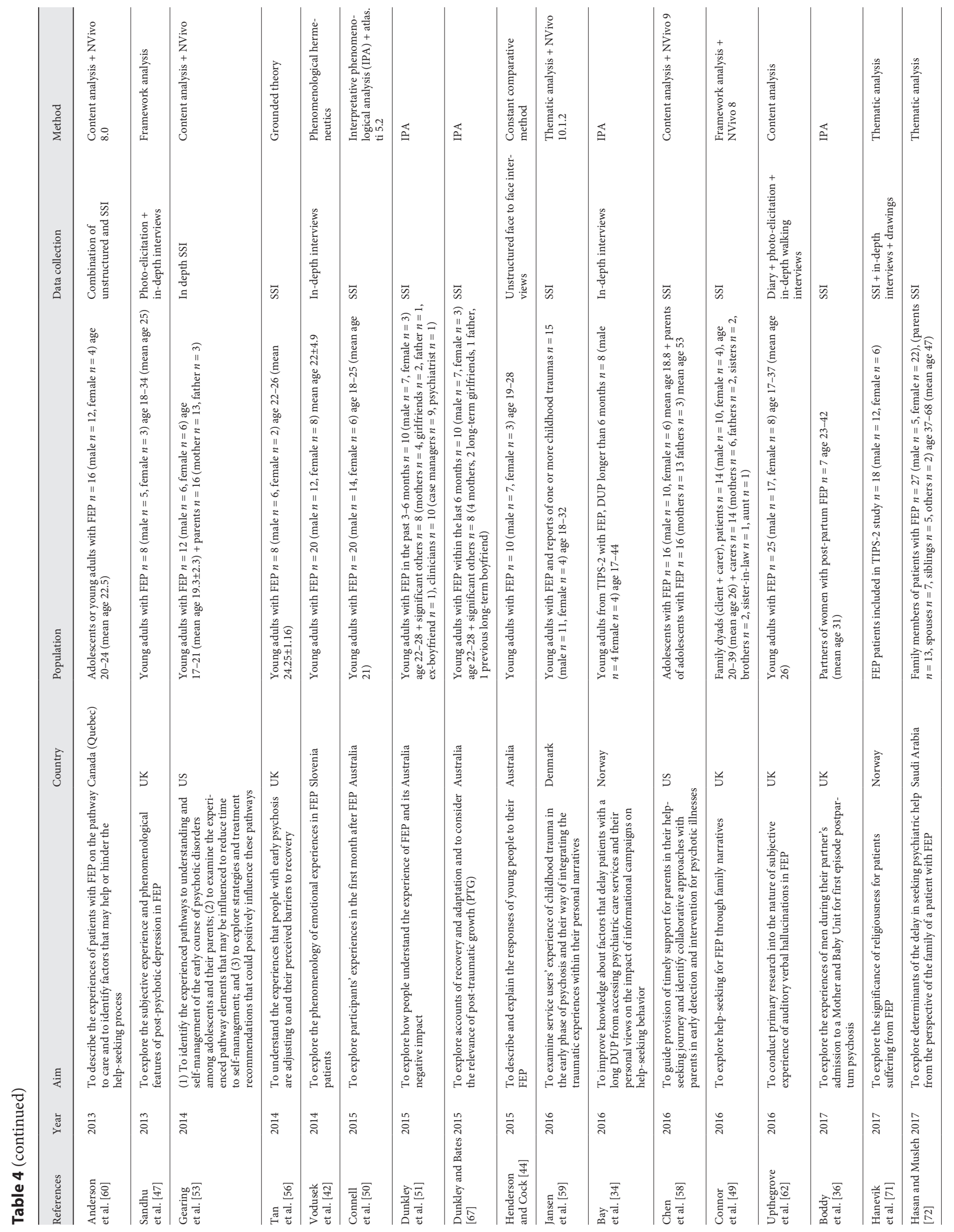




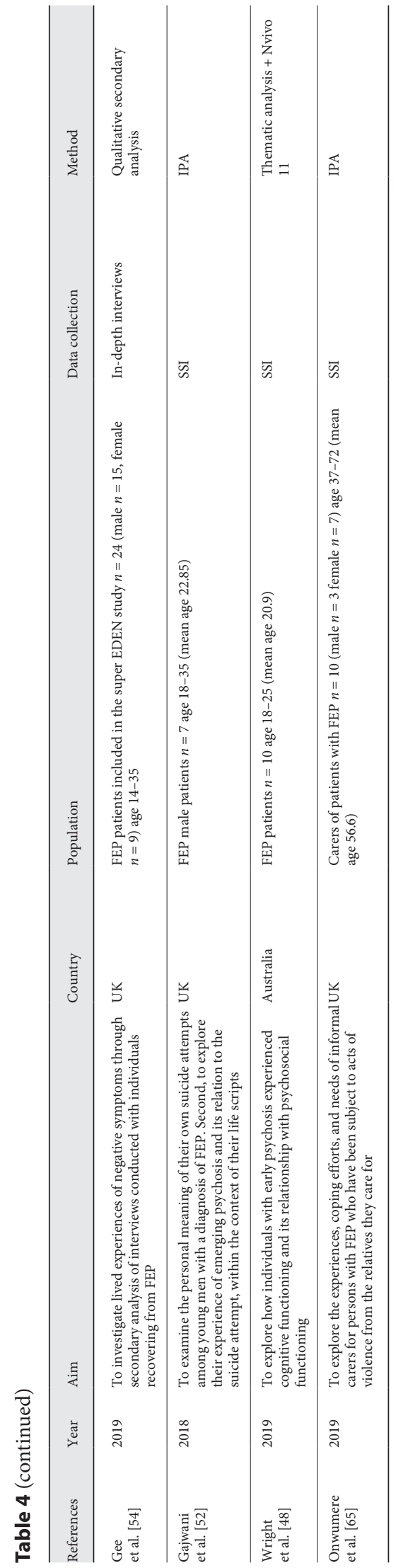

The Lived Experience of First-Episode Psychosis
$38,45,48]$. The families described exterior trigger phenomena, such as expulsion from school for behavioral problems [36].

The patients, on the other hand, did not describe a sudden start, but instead reported experiencing a break or rupture with their previous functioning:

- The impression that they were no longer themselves $[41,51,52,54,58,62]$

- The impression of being lost, confused [46, 49, 50], unreal, disconnected from themselves, from others, and from the world around them [51, 52].

This break also involved an experience of loss and of grief:

- A loss related to changes in their personality or in their abilities, induced by their experience with the disease $[46,47,50,53]$

- Loss of confidence in themselves [51,53]

- Loss of their previous physical appearance [51-53]

- Mourning for a "normal" adolescence [44], for the feeling of being a "normal" person [50].

Family and close friends also reported this experience of grief and loss. Siblings in particular described their mourning for the relationship they had had with their brother or sister and for a "normal" adolescence. Parents linked acceptance of their child's chronic disease with numerous successive painful renunciations, especially of the relationship they had established before the disease and the future they had imagined for their child [53].

Not a Beginning but a Continuation?

Families focused their narratives on the child's preexisting difficulties. Parents described the child's developmental difficulties, or even authentic disorders [37, 55], with their histories of psychiatric care for learning disorders, tics, anxiety, language disorders, epilepsy, and so on. Most also noted their child's early relationship difficulties [37].

The patients reported trauma before their FEPs, often repeated or prolonged, such as abuse (physical or emotional) or deaths $[50,54,56]$. They also described problems with relationships since childhood $[39,42,50,56]$ :

With peers: They described experiences of harassment, rejection, hostility, or being mocked [39].

With their family: They reported conflictual relationships with their parents, abuse, and parental psychiatric diseases $[39,50,56]$.

Finally, several patients recounted continuity between before and after the first psychotic episode. They noted that they did not feel different and that they had always had psychotic symptoms and concentration or mood disorders that were a problem in their daily lives [61]. 
Table 5. Quotations by participants and authors of the studies illustrating each theme

\begin{tabular}{|c|c|c|}
\hline & Quotations from participants in primary studies & Interpretations of findings offered by authors \\
\hline \multicolumn{3}{|l|}{ 1. When and how does a FEP start? } \\
\hline A sudden beginning, a break? & $\begin{array}{l}\text { Parent: "We were just really trying to get [him] to a doctor or anybody, whoever we } \\
\text { thought, such as the disability office. Until that happened, I hate to say it, but that's the } \\
\text { only thing that helped him - when he came up with that gun." (Bergner et al. [35]) } \\
\text { Parent: "He was suspended from school for a few weeks and it was then, he just dropped } \\
\text { and went on an almighty low and that was when he tried to commit suicide then." } \\
\text { (Cadario et al. [37]) }\end{array}$ & $\begin{array}{l}\text { Only when positive symptoms presented as potentially dangerous or violent } \\
\text { behaviors were family members moved to take action. (Bergner et al. [35]) }\end{array}$ \\
\hline $\begin{array}{l}\text { Not a beginning but a } \\
\text { continuation? }\end{array}$ & $\begin{array}{l}\text { Patient: "I didn't really have any close friends. I was bullied at school so that prevented } \\
\text { me from having close friends." (Mackrell et al. [40]) } \\
\text { Patient: "Well, I can't really pinpoint "a before", if there was "a before", or if there was } \\
\text { just "leading up to it". Even as a child I didn't really feel normal or like other kids, so not } \\
\text { knowing if I was just normally really withdrawn and then developed something else, or } \\
\text { if, you know, I always had some sort of seed within me that just, kind of, unfurled } \\
\text { naturally." (Brown [43]) } \\
\text { Parent: "I just sort of thought that this was sort of an extension of his personality, just a } \\
\text { little bit sort of exaggerated. But you think, kids do play up, it's that age, you know." } \\
\text { (Cadario et al. [37]) }\end{array}$ & $\begin{array}{l}\text { Participants in this study did not reconstruct or redefine their sense of self in the } \\
\text { context of mental illness. Rather, their sense of self endured as they continued to } \\
\text { pursue their interests, life goals and ambitions as emergent young adults and were } \\
\text { encouraged by clinicians and others around them to do so. (Romano et al. [46]) } \\
\text { These family narratives about patients were remarkably consistent in describing an } \\
\text { essentially normal but vulnerable premorbid period in childhood, followed by the } \\
\text { slow emergence of non-specific symptoms in teen years, such as social withdrawal, } \\
\text { functional decline and mood symptoms. (Corcoran et al. [38]) } \\
\text { Findings showed that when children grew up in treatment for childhood conditions, } \\
\text { parents were less likely to report awareness in the initial phase. (Chen et al. [58]) }\end{array}$ \\
\hline \multicolumn{3}{|c|}{ 2. What are its negative and positive aspects? } \\
\hline $\begin{array}{l}\text { A painful experience } \\
\text { of distress }\end{array}$ & $\begin{array}{l}\text { Patient: "I am never really sad, because I am emotionally numb. I feel a certain sadness } \\
\text { almost all the time though - I'm sad because of this numbness (....)." (Vodusek et al. } \\
\text { [42]) } \\
\text { A sister: “... it was just so like distressing because it was so just like different to normal } \\
\text { and what he's normally like" (Newman et al. [41]) } \\
\text { A sister: "I couldn’t sleep in the night... I would be crying day and night, I think because I } \\
\text { used to go there [hospital] and the things she was saying... I had so many problems, I } \\
\text { couldn't eat or sleep, and that just affected me badly." (Sin et al. [63]) }\end{array}$ & $\begin{array}{l}\text { We observed in this study that an overwhelming sense of shame strengthened } \\
\text { participants' feelings of loss and social withdrawal. (Sandhu et al. [47]) } \\
\text { Our analysis of emotion experience (...) is in line with the two general findings in } \\
\text { the literature: (1) there is a prevalence of negative emotion experience (especially } \\
\text { anxiety and undifferentiated sadness) in both the pre- and post-psychotic self and } \\
\text { (2) emotion experiences in general are both subjectively unstable and hard to access } \\
\text { and have a disorganizing effect on reflective processes. (Vodusek et al. [42]) } \\
\text { The current findings demonstrate, however, that the traumagenic distress of FEP is } \\
\text { not confined to a short period but operates in the longer term, as most themes } \\
\text { related to the aftermath of this experience (Dunkley et al. [51]) }\end{array}$ \\
\hline A positive experience? & $\begin{array}{l}\text { A younger sister: "It's made me grow up quicker; it has some good effect as well because } \\
\text { it's made me... open up to how people feel and be more aware." (Sin et al. [63]) } \\
\text { Patient: "Well it's helped since I've told my mum. I only told my mum about how I've } \\
\text { been feeling a few months ago, so it's just really changed since she's known. She was } \\
\text { really supportive and could understand that it's an illness and that you need to get some } \\
\text { help." (Lester et al. [57]) }\end{array}$ & $\begin{array}{l}\text { Some of the positive outcomes identified include enhancement of relationships and } \\
\text { change of self-perception and life philosophy. (Newman et al. [41]) } \\
\text { [B]ecoming closer reflects an unanticipated reward of caregiving. It may mean a } \\
\text { period of personal growth and strengthening of an existing good relationship or in } \\
\text { some circumstances bring the carer and young person closer together in a more } \\
\text { open and deeper relationship than before. (McCann et al. [64]) }\end{array}$ \\
\hline \multicolumn{3}{|c|}{ 3. How do patients and families recount an FEP? } \\
\hline $\begin{array}{l}\text { The difficulty of } \\
\text { putting it into words }\end{array}$ & $\begin{array}{l}\text { Patient: "The first step was the most difficult for me. I had trouble finding the right } \\
\text { words. How does one start such a conversation? You can't just start it by saying 'By the } \\
\text { way..." (Bay et al. [34]) }\end{array}$ & $\begin{array}{l}\text { However, the young people themselves often lacked the words or language with } \\
\text { which they could describe the things that were happening to them and were also, } \\
\text { sometimes, reluctant to open-up for fear of upsetting the family member who had } \\
\text { accompanied them. (Connor et al. [49]) }\end{array}$ \\
\hline Make sense of it? & $\begin{array}{l}\text { Patient: "I think this happened for a reason, probably a good reason - to stop doing what } \\
\text { I was doing. It was like teaching me a lesson, "this is what it does." (Connell et al. [50]) }\end{array}$ & $\begin{array}{l}\text { The main characteristic of patients' religiousness is that they explain their } \\
\text { experiences of hallucinations as mystical experiences. (Hanevik et al. [71]) }\end{array}$ \\
\hline
\end{tabular}

\section{What Are Its Negative and Positive Aspects?}

A Painful Experience of Distress

Patients described their FEP as an experience of major distress and numerous negative emotions:

- Fear [45, 46, 62]

- Anxiety [41]

- Sense of despair [51,62]

- A feeling of shame and humiliation after the episode $[46,57,58]$

- Sadness at the moment they became aware of the challenges presented by recovery [45]

- Worry about their future $[62,63]$, specifically fear that they would never again be happy [42] and concern about the social consequences of this episode (such as job loss or stigmatization) [51, 52].

Finally, the patients reported a feeling of very intense distress induced by the psychotic symptoms [50], such as paranoia, hallucinations, and disorganization [51]. Auditory hallucinations with delusional commands or violent, threatening, or degrading comments generated substantial emotional distress [65].

The siblings reported experiencing the FEP as an intense shock induced by their inability to understand what was happening [40]. They described a feeling of shame, fear of embarrassing behavior by their sibling [64], and worry about the well-being of the youngest siblings and about their own mental health [40]. They also revealed a sense of ambivalence, between, on the one hand, the desire to help their sick brother or sister and their parents and, on the other hand, a feeling of jealousy due to how their parents' attention was monopolized and to their desire to move ahead in their own lives [40]. Some siblings described guilt feeling about their inadequate empathy [64].

Parents described their dismay at their child's symptoms before finding care [60], but also their shock at the child's hospitalization, often on an emergency basis [37, 62 ]. They talked about how their role as principal caregiv- 


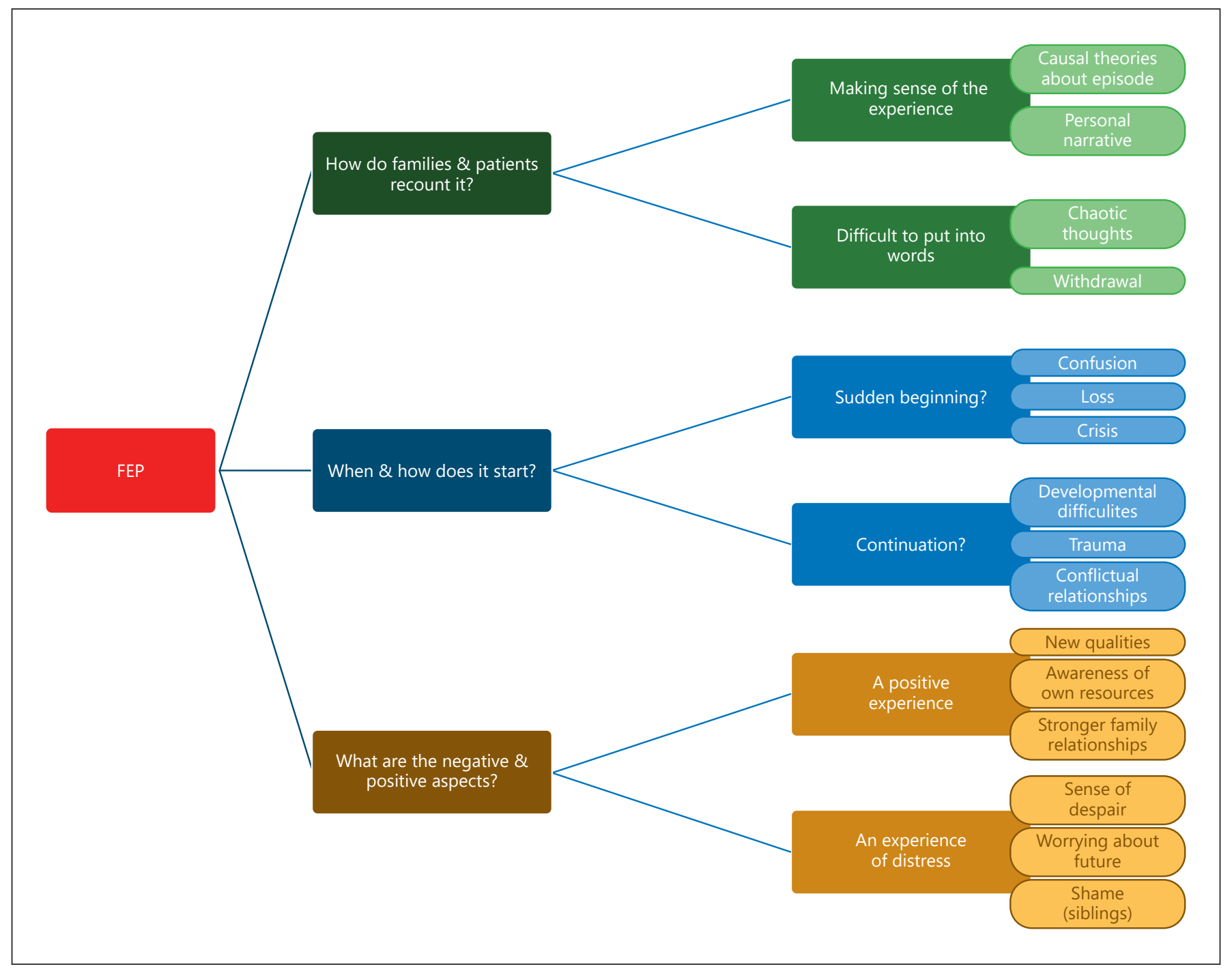

Fig. 2. Overview of the results.

ers especially exposed them to emotional distress, sadness in particular, $[36,61,62]$. They described this role as a burden and talked about physical and psychological [60, 61] exhaustion associated with feelings of anger, worry, and fear about their child's aggressiveness toward them $[36,60,61]$. Finally, they described especially intense guilt feelings $[48,60]$ as well as great worry about their child's future [37].

\section{A Positive Experience?}

A minority of patients nonetheless reported experiencing the psychotic outbreak as positive, at least temporarily, because they felt more authentic than they had be- fore [41]. Similarly, several patients experienced their auditory hallucinations positively, describing the voices as helpful, supportive, and protective [65].

Some patients seized the episode as an opportunity for change $[58,63]$, for example, by adopting a healthier lifestyle [45], such as better sleep hygiene [50]. It was especially retrospectively that they described their developing awareness of the positive aspects of this FEP experience:

- Acquisition of new qualities, such as empathy, attention to others $[62,66,67]$, self-confidence $[50,67]$, or maturity $[63,66]$

- Better awareness of their own resources [45]

- Better knowledge of themselves [50,67] 
- A stronger self $[45,58]$

- Increased desire for relationships [44, 67]

- Enhanced personal ties with their families and friends $[42,53,58,60,64]$

- Creation of new ties to peers who have gone through the same problems $[54,57,67]$.

They had the feeling that they had overcome hardships $[58,67]$ and talked about a new outlook on life, a feeling that they could enjoy it more than before [66].

The families also described the strengthening of bonds between siblings [64] and between parents and children $[42,53,60]$. Parents did not report any additional positive aspects, although the siblings said that the experience had contributed to their personal development [64]. They had the impression that they had become more understanding, thoughtful, and "had grown up faster" [64].

\section{How Do Patients and Families Recount FEPs?}

The Difficulty of Putting It into Words

The patients reported that it was difficult to talk about what they had experienced to their family and friends or to healthcare professionals $[33,36,48,55,62,68]$. Putting it into words amounted only to a description of their symptoms. They could say only that they had had chaotic thoughts that they could no longer control [50], had "heard voices" $[45,69]$ or felt "paranoid" $[39,43,69]$.

Families had little access to the patient's experience and were mainly able to report withdrawal [62] and sometimes hallucinations [62]. They were aware that "something was wrong," but they did not know what [45].

\section{Making Sense of What Has Been Experienced?}

More than putting it into words, many patients described the importance of making sense of what they had experienced, giving it a meaning to be able to move forward $[45,70]$. Some patients developed personal theories about the cause of their episode, which helped them to find a meaning and to restore a coherent personal narrative [58]. Others considered the FEP a mystical experience, even after remission of their symptoms [72].

The siblings integrated their sister or brother's FEP within their life narrative, to give it a meaning, for example, by discovering a professional vocation in mental health, induced by this illness in their family [40]. Others had become informed and acquired medical knowledge to enable them to accept the disease better [40].

Finally, some very religious parents accepted their child's disease more easily by giving it a religious meaning [71].

\section{Discussion}

The results of this metasynthesis enumerate the many questions that patients and their families raise about FEPs. Two points appear to us to be essential to discuss: its simultaneous negative and positive aspects, and the discrepancy between the name "first episode of psychosis" and the experience reported.

\section{An Experience Simultaneously Positive and Negative}

The negative aspects of FEPs found in the accounts by patients and their families are well known in the literature and highly present in qualitative studies. One metasynthesis has already been devoted entirely to this subject [28]. Similarly, the positive changes identified retrospectively by patients have already been the topic of many studies and of a recent systematic review [29]. Nonetheless, our results also demonstrate that only a minority of patients found the psychotic experience itself positive, that is, the feeling of authenticity and the positive perception of auditory hallucinations. They further show a major difference between the experiences of the patients and those of their families. That is, while many - almost all patients related at least some positive elements of their FEPs, these aspects are almost totally absent from the families' accounts.

Healthcare providers must be aware of these 2 original aspects as both need to be addressed during treatment to ensure and maintain the patients' adherence to care and to offer appropriate support to the families.

\section{The Gap between the Name and the Experience}

The lack of detailed descriptions of the FEP experience by the patients, together with their difficulty of putting it into words, raises questions. Three avenues might help to understand this: (i) It might be related to methodological problems: research interviews of people with schizophrenia might benefit from methodological innovations [73], by the use of narrative aids, such as photo-elicitation, daily journals, and interviews while walking, which have been used successfully in this clinical population [29]. (ii) This difficulty may also be related to the types of disorders presented by the patients interviewed, but the authors of these studies never mention this. (iii) Finally, the difficulty of putting the experience into words may be explained by a discrepancy between the term "FEP" and the patients' experience. Our results suggest that the term "first episode" may often be inappropriate, for many patients described experiencing both continuity and rupture, but a rupture without any real beginning. In other 
words, this may not necessarily be an "episode," and the patients may have had similar experiences before this socalled "first" episode.

The term FEP has been criticized quite heavily in the literature. First of all, there is no consensual definition. Breitborde et al. [74] found 3 different definitions of FEP in the literature: (1) first contact with the psychiatric or mental healthcare system, (2) time since the onset of antipsychotic treatment, and (3) time since the onset of psychotic symptoms. This author advocated the use of "recent onset psychosis" instead of FEP, as more consistent with clinical aspects and with the forms with an insidious onset. Our results reinforce this criticism. Moreover, the emergence of the concept may, according to some authors, be linked to medical research and to the needs of the pharmaceutical industry to obtain homogeneous patient populations for randomized clinical trials. In a recent article, Berkhout [75] proposed a sociohistorical analysis of the development of the concept of FEP. According to her, this term "emerges as a distinct chronological stage of psychotic illness in the late 1980s in response to challenges within schizophrenia research (p2)." FEP may thus be understood not as a clinical entity or a diagnostic category but rather as a research strategy associated with the "paradigm shift" toward early intervention [75]. Berkhout suggests that FEP is "a product of a particular sociohistorical moment rather than reflective of an independent reality that can be explained in purely scientific terms." In the same spirit, the Australian guidelines on treatment of FEP [76] define it as the first treated episode experienced by an individual during his or her lifetime. That is, it is not the first episode but the first episode known and handled by the healthcare system. Accordingly, implicitly, FEP does not name the patient's lived experience but rather the intervention. Moreover, our results suggest that this aggravates the confusion of these patients, who do not recognize their experience in the diagnosis they are given. This is related to the impact of diagnostic labeling (see ref. [77]) but adds to it specific questions about the effect of a term imposed on patients even though it makes no sense for them. We think that this terminological obstacle can directly impact these patients' long-term adherence to care. This also echoes the work of Ian Hacking, about mutual interactions between human phenomena and their classifications [78].

\section{Implications}

When specialized FEP services are implemented, we would therefore recommend giving special attention to naming the service. We would recommend avoiding

The Lived Experience of First-Episode Psychosis terms such as "first episode psychosis clinic," but rather choose "early intervention in psychosis service." The best option to fit recovery and empowerment principles would even be to let service users choose the name of the unit during the creation process. The variety of experiences among individuals is so wide that labeling the experience will necessarily be unsatisfying. Thus, our options are either to choose a term voluntarily vague and general, or to name, not the experience of the illness (as would "first episode psychosis" does), but the experience of care (as "first treated episode" does).

The same applies in clinical practice: naming the experience of care rather than the experience of illness should also be the ground rule while taking care of these patients so to avoid confusion and dropouts. Moreover, psychiatrists must be aware that there is a "looping effect" between the lived experience of the patient and the diagnostic label [78], so when patients receive a diagnosis, they interact with it, it affects their experience, and ultimately their experience affects the diagnosis. We would thus recommend therapeutic approaches enabling patients and their family to formulate their own narrative of the psychotic experience, such as the Open Dialogue approach [79].

\section{Strengths and Limitations}

This review integrates the views about FEP from 378 patients and 176 relatives. The method we applied is rigorous, tested in medical research [80], and meets the criteria of the ENTREQ guidelines. We analyzed 38 articles, all published in peer-reviewed journals and mostly of good quality.

However, certain aspects of this metasynthesis limit the generalization of its conclusions. A qualitative metasynthesis collects only partial data from the participants and the interpretations of the researchers, which are the data given in the initial articles. Moreover, we note that although the review includes articles from diverse cultural areas, articles from English-speaking countries are overrepresented. It is nonetheless likely that the literature accessible through these international databases would overrepresent English-speaking countries even if we had selected articles in all languages.

Finally, our review did not integrate the lived experience of healthcare professionals. To our knowledge, there are only 3 qualitative studies [81-83] on that topic, and all 3 consider the experience of care more than that of the disease. Further qualitative research is needed within this population to cross perspectives with patients and families. 


\section{Conclusion}

This metasynthesis has enabled us to identify a specific issue concerning the use of a term such as FEP, which comes from neither a clinical nor an experiential framework. There is a danger in using terms developed for the organization of care and public health issues as clinical entities and diagnostic categories. In our opinion, this can aggravate the confusion of patients and their families and have a harmful effect on their continuation of care. Recent decades have seen a movement in medicine from a doctor-centered to a patient-centered approach focusing on shared decision-making and patient participation and in which doctors try to see the illness through their patients' eyes. In the same spirit, psychiatric nosography must be thought out and developed from what patients experience rather than from the needs or expectations of the healthcare system, or it may end up creating a gap between experience and label that may be harmful for patients. As Albert Camus wrote, "Misnaming an object adds to the misery of this world" [84].

\section{Acknowledgment}

The authors would like to thank Jo Ann Cahn for her rigorous translation.

\section{Conflict of Interest Statement}

The authors have no conflicts of interest to declare.

\section{Funding Sources}

There are no funding sources to declare.

\section{Author Contributions}

J.S. and A.R.-L. designed the study; A.N., I.O., E.M., and J.S. searched the databases and selected the articles. A.N., L.V., and J.S. coded the papers to define the themes and wrote the article in collaboration. L.V., A.R.-L., and J.S. supervised the study. A.N. and J.S. wrote the original draft, and all authors reviewed and edited the final version.

\section{References}

1 Kirkbride JB, Hameed Y, Ankireddypalli G, Ioannidis K, Crane CM, Nasir M, et al. The Epidemiology of First-Episode Psychosis in Early Intervention in Psychosis Services: Findings From the Social Epidemiology of Psychoses in East Anglia [SEPEA] Study. Am J Psychiatry. 2017 Feb;174(2):143-53.

2 Anderson KK, Norman R, MacDougall A, Edwards J, Palaniyappan L, Lau C, et al. Effectiveness of Early Psychosis Intervention: Comparison of Service Users and Nonusers in Population-Based Health Administrative Data. Am J Psychiatry. 2018 May;175(5):443-52.

3 Hubbard DB, Miller BJ. Meta-analysis of blood cortisol levels in individuals with firstepisode psychosis. Psychoneuroendocrinology. 2019 Jun;104:269-75.

4 Kopczynska M, Zelek W, Touchard S, Gaughran F, Di Forti M, Mondelli V, et al. Complement system biomarkers in first episode psychosis. Schizophr Res. 2019 Feb;204: $16-22$.

5 Makowski C, Lewis JD, Lepage C, Malla AK, Joober R, Lepage M, et al. Structural Associations of Cortical Contrast and Thickness in First Episode Psychosis. Cereb Cortex. 2019 Dec; 21(12): 5009-5021. https://doi. org/10.1093/cercor/bhz040

6 Sauras R, Keymer A, Alonso-Solis A, Díaz A, Molins C, Nuñez F, et al. Volumetric and morphological characteristics of the hippocampus are associated with progression to schizophrenia in patients with first-episode psychosis. Eur Psychiatry. 2017 Sep;45:1-5.
7 Ota VK, Noto C, Santoro ML, Spindola LM, Gouvea ES, Carvalho CM, et al. Increased expression of NDEL1 and MBP genes in the peripheral blood of antipsychotic-naïve patients with first-episode psychosis. Eur Neuropsychopharmacol. 2015 Dec;25(12):2416-25.

8 Sengupta SM, MacDonald K, Fathalli F, Yim A, Lepage M, Iyer S, et al. Polygenic Risk Score associated with specific symptom dimensions in first-episode psychosis. Schizophr Res. 2017 Jun;184:116-21.

9 Vassos E, Di Forti M, Coleman J, Iyegbe C, Prata D, Euesden J, et al. An Examination of Polygenic Score Risk Prediction in Individuals With First-Episode Psychosis. Biol Psychiatry. 2017 Mar;81(6):470-7.

10 Allott K, Fraguas D, Bartholomeusz CF, DíazCaneja CM, Wannan C, Parrish EM, et al. Duration of untreated psychosis and neurocognitive functioning in first-episode psychosis: a systematic review and meta-analysis. Psychol Med. 2018 Jul;48(10):1592-607.

11 Tonna M, Ossola P, Marchesi C, Bettini E, Lasalvia A, Bonetto C, et al. Dimensional structure of first episode psychosis. Early Interv Psychiatry. 2019 Dec; 13(6): 1431-1438. https://doi.org/10.1111/eip.12789

12 Bozzatello P, Bellino S, Rocca P. Predictive Factors of Treatment Resistance in First Episode of Psychosis: A Systematic Review. Front Psychiatry. 2019 Feb;10:67. https://doi. org/10.3389/fpsyt.2019.00067.
13 Griffiths R, Mansell W, Carey TA, Edge D, Emsley R, Tai SJ. Method of levels therapy for first-episode psychosis: the feasibility randomized controlled Next Level trial. J Clin Psychol. 2019 Oct;75(10):1756-69.

14 Holt RI, Gossage-Worrall R, Hind D, Bradburn MJ, McCrone P, Morris T, et al. Structured lifestyle education for people with schizophrenia, schizoaffective disorder and first-episode psychosis (STEPWISE): randomised controlled trial. Br J Psychiatry. 2019 Feb;214(2):63-73.

15 Hui CL, Lam BS, Lee EH, Chan SK, Chang WC, Suen YN, et al. A systematic review of clinical guidelines on choice, dose, and duration of antipsychotics treatment in first- and multi-episode schizophrenia. Int Rev Psychiatry. 2019 Aug - Sep;31(5-6):441-59.

16 Puntis S, Minichino A, Crescenzo FD, Cipriani A, Lennox B. Specialised early intervention teams (extended time) for first episode psychosis. Cochrane Database Syst Rev [Internet]. 2019 [cité 30 avr 2019];(3). Disponible sur: https://www.cochranelibrary.com/cdsr/ doi/10.1002/14651858.CD013287/full.

17 Correll CU, Galling B, Pawar A, Krivko A, Bonetto C, Ruggeri M, et al. Comparison of Early Intervention Services vs Treatment as Usual for Early-Phase Psychosis: A Systematic Review, Meta-analysis, and Meta-regression. JAMA Psychiatry. 2018 Jun;75(6):55565. 
18 Andresen R, Caputi P, Oades L. Stages of recovery instrument: development of a measure of recovery from serious mental illness. Aust N Z J Psychiatry. 2006 Nov-Dec;40(11-12): 972-80.

19 Andresen R, Caputi P, Oades LG. Do clinical outcome measures assess consumer-defined recovery? Psychiatry Res. 2010 May;177(3): $309-17$.

20 Castro EM, Van Regenmortel T, Vanhaecht K, Sermeus W, Van Hecke A. Patient empowerment, patient participation and patientcenteredness in hospital care: A concept analysis based on a literature review. Patient Educ Couns. 2016 Dec;99(12):1923-39.

21 Barry MJ, Edgman-Levitan S. Shared decision making - pinnacle of patient-centered care. N Engl J Med. 2012 Mar;366(9):780-1.

22 Baines R, Donovan J, Regan de Bere S, Archer J, Jones R. Patient and public involvement in the design, administration and evaluation of patient feedback tools, an example in psychiatry: a systematic review and critical interpretative synthesis. J Health Serv Res Policy. 2019 Apr;24(2):130-42.

23 van Veen M, Peters A, Mulder N, van Meijel B, Koekkoek B. A Qualitative Study of the Working Alliance between Patient and Community Mental Health Nurse during Interpersonal Community Psychiatric Treatment. Issues Ment Health Nurs. 2020 Mar;41(3): 211-20.

24 Langlois EV, Tunçalp Ö, Norris SL, Askew I, Ghaffar A. Qualitative evidence to improve guidelines and health decision-making. Bul World Health Organ. 2018 Feb;96(2):79$79 \mathrm{~A}$.

25 Thomas J, Harden A. Methods for the thematic synthesis of qualitative research in systematic reviews. BMC Med Res Methodol. 2008 Jul;8(1):45.

26 NICE. Asthma: diagnosis, monitoring and chronic asthma management | Guidance and guidelines | NICE [Internet]. 2017 [cité 6 avr 2018]. Report No.: NG80. Disponible sur: https://www.nice.org.uk/guidance/ng80.

27 NICE. Diabetes in Pregnancy: Management of Diabetes and Its Complications from Preconception to the Postnatal Period [Internet]. London: National Institute for Health and Care Excellence (UK); 2015 [cité 20 févr 2018]. (National Institute for Health and Care Excellence: Clinical Guidelines). Disponible sur: http://www.ncbi.nlm.nih.gov/books/ NBK293625.

28 Boydell KM, Stasiulis E, Volpe T, Gladstone B. A descriptive review of qualitative studies in first episode psychosis. Early Interv Psychiatry. 2010 Feb;4(1):7-24.

29 Griffiths R, Mansell W, Edge D, Tai S. Sources of Distress in First-Episode Psychosis: A Systematic Review and Qualitative Metasynthesis. Qual Health Res. 2019 Jan;29(1):10723.

The Lived Experience of First-Episode Psychosis
30 Jordan G, MacDonald K, Pope MA, Schorr E, Malla AK, Iyer SN. Positive Changes Experienced After a First Episode of Psychosis: A Systematic Review. Psychiatr Serv. 2018 Jan; 69(1):84-99.

31 Sibeoni J, Orri M, Valentin M, Podlipski MA Colin S, Pradere J, et al. Metasynthesis of the Views about Treatment of Anorexia Nervosa in Adolescents: Perspectives of Adolescents, Parents, and Professionals. PLoS One. 2017 Jan;12(1):e0169493.

32 Bousquet G, Orri M, Winterman S, Brugière C, Verneuil L, Revah-Levy A. Breaking Bad News in Oncology: A Metasynthesis. J Clin Oncol. 2015 Aug;33(22):2437-43.

33 Chenail RJ. Learning to appraise the quality of qualitative research articles: A contextualized learning object for constructing knowledge. Qual Rep. 2011 Jan;16(1):236-48.

34 Bay N, Bjørnestad J, Johannessen JO, Larsen TK, Joa I. Obstacles to care in first-episode psychosis patients with a long duration of untreated psychosis. Early Interv Psychiatry. $2016 \mathrm{Feb} ; 10(1): 71-6$.

35 Bergner E, Leiner AS, Carter T, Franz L, Thompson NJ, Compton MT. The period of untreated psychosis before treatment initiation: a qualitative study of family members' perspectives. Compr Psychiatry. 2008 NovDec;49(6):530-6.

36 Boddy R, Gordon C, MacCallum F, McGuinness M. Men's experiences of having a partner who requires Mother and Baby Unit admission for first episode postpartum psychosis. J Adv Nurs. 2017 Feb;73(2):399-409.

37 Cadario E, Stanton J, Nicholls P, Crengle S, Wouldes T, Gillard M, et al. A qualitative investigation of first-episode psychosis in adolescents. Clin Child Psychol Psychiatry. 2012 Jan;17(1):81-102.

38 Corcoran C, Gerson R, Sills-Shahar R, Nickou C, McGlashan T, Malaspina D, et al. Trajectory to a first episode of psychosis: a qualitative research study with families. Early Interv Psychiatry. 2007 Nov;1(4):308-15.

39 Franz L, Carter T, Leiner AS, Bergner E, Thompson NJ, Compton MT. Stigma and treatment delay in first-episode psychosis: a grounded theory study. Early Interv Psychiatry. 2010 Feb;4(1):47-56

40 Mackrell L, Lavender T. Peer relationships in adolescents experiencing a first episode of psychosis. J Ment Health. 2004 Jan;13(5): 467-79.

41 Newman S, Simonds LM, Billings J. A narrative analysis investigating the impact of first episode psychosis on siblings' identity. Psychosis. 2011 Oct;3(3):216-25.

42 Vodušek VV, Parnas J, Tomori M, Škodlar B. The phenomenology of emotion experience in first-episode psychosis. Psychopathology. 2014;47(4):252-60

43 Brown JA. Talking about life after early psychosis: the impact on occupational performance. Can J Occup Ther. 2011 Jun;78(3): $156-63$
44 Henderson AR, Cock A. The responses of young people to their experiences of first-episode psychosis: harnessing resilience. Community Ment Health J. 2015 Apr;51(3):322-8.

45 MacDonald E, Sauer K, Howie L, Albiston D. What happens to social relationships in early psychosis? A phenomenological study of young people's experiences. J Ment Health. 2005 Apr;14(2):129-43.

46 Romano DM, McCay E, Goering P, Boydell K, Zipursky R. Reshaping an enduring sense of self: the process of recovery from a first episode of schizophrenia. Early Interv Psychiatry. 2010 Aug;4(3):243-50.

47 Sandhu A, Ives J, Birchwood M, Upthegrove $\mathrm{R}$. The subjective experience and phenomenology of depression following first episode psychosis: a qualitative study using photoelicitation. J Affect Disord. 2013 Jul;149(1-3): 166-74.

48 Wright AL, Phillips LJ, Bryce S, Morey-Nase C, Allott K. Subjective experiences of cognitive functioning in early psychosis: a qualitative study. Psychosis. 2019 Jan;11(1):63-74.

49 Connor C, Greenfield S, Lester H, Channa S, Palmer C, Barker C, et al. Seeking help for firstepisode psychosis: a family narrative. Early Interv Psychiatry. 2016 Aug;10(4):334-45.

50 Connell M, Schweitzer R, King R. Recovery from first-episode psychosis and recovering self: A qualitative study. Psychiatr Rehabil J. 2015 Dec;38(4):359-64.

51 Dunkley JE, Bates GW, Findlay BM. Understanding the trauma of first-episode psychosis. Early Interv Psychiatry. 2015 Jun;9(3) 211-20.

52 Gajwani R, Larkin M, Jackson C. "What is the point of life?": an interpretative phenomenological analysis of suicide in young menwith first-episode psychosis. Early Interv Psychiatry. 2018 Dec;12(6):1120-7.

53 Gearing RE, DeVylder JE, Chen F, Pogge DL, Buccolo M. Changing perceptions of illness in the early course of psychosis: psychological pathways to self-determination and self-management of treatment. Psychiatry. 2014;77(4): 344-59.

54 Gee B, Hodgekins J, Lavis A, Notley C, Birchwood M, Everard L, et al. Lived experiences of negative symptoms in first-episode psychosis: A qualitative secondary analysis. Early Interv Psychiatry. 2019 Aug;13(4):773-9.

55 Boydell KM, Gladstone BM, Volpe T. Understanding help seeking delay in the prodrome to first episode psychosis: a secondary analysis of the perspectives of young people. Psychiatr Rehabil J. 2006;30(1):54-60.

56 Tan R, Gould RV, Combes H, Lehmann S. Distress, trauma, and recovery: adjustment to first episode psychosis. Psychol Psychother. 2014 Mar;87(1):80-95.

57 Lester H, Marshall M, Jones P, Fowler D, Amos T, Khan N, et al. Views of young people in early intervention services for first-episode psychosis in England. Psychiatr Serv. 2011 Aug;62(8):882-7. 
58 Chen FP, Gearing RE, DeVylder JE, Oh HY. Pathway model of parental help seeking for adolescents experiencing first-episode psychosis. Early Interv Psychiatry. 2016 Apr; 10(2):122-8.

59 Jansen JE, Pedersen MB, Trauelsen AM, Nielsen HG, Haahr UH, Simonsen E. The Experience of Childhood Trauma and Its Influence on the Course of Illness in First-Episode Psychosis: A Qualitative Study. J Nerv Ment Dis. 2016 Mar;204(3):210-6.

60 Anderson KK, Fuhrer R, Malla AK. "There are too many steps before you get to where you need to be": help-seeking by patients with first-episode psychosis. J Ment Health. 2013 Aug;22(4):384-95.

61 Eisenstadt P, Monteiro VB, Diniz MJ, Chaves AC. Experience of recovery from a first-episode psychosis. Early Interv Psychiatry. 2012 Nov;6(4):476-80.

62 Upthegrove R, Ives J, Broome MR, Caldwell K, Wood SJ, Oyebode F. Auditory verbal hallucinations in first-episode psychosis: a phenomenological investigation. BJPsych Open. 2016 Feb;2(1):88-95.

63 Sin J, Moone N, Harris P. Siblings of individuals with first-episode psychosis: understanding their experiences and needs. J Psychosoc Nurs Ment Health Serv. 2008 Jun;46(6):3340.

64 McCann TV, Lubman DI, Clark E. First-time primary caregivers' experience of caring for young adults with first-episode psychosis. Schizophr Bull. 2011 Mar;37(2):381-8.

65 Onwumere J, Parkyn G, Learmonth S, Kuipers E. The last taboo: the experience of violence in first-episode psychosis caregiving relationships. Psychol Psychother. 2019 Mar; 92(1):1-19.
66 Lam MM, Pearson V, Ng RM, Chiu CP, Law $\mathrm{CW}$, Chen EY. What does recovery from psychosis mean? Perceptions of young first-episode patients. Int J Soc Psychiatry. 2011 Nov; 57(6):580-7.

67 Dunkley JE, Bates GW. Recovery and adaptation after first-episode psychosis: the relevance of posttraumatic growth. Psychosis. $2015 \mathrm{Apr} ; 7(2): 130-40$.

68 Judge AM, Estroff SE, Perkins DO, Penn DL. Recognizing and responding to early psychosis: a qualitative analysis of individual narratives. Psychiatr Serv. 2008 Jan;59(1):96-9.

69 Hirschfeld R, Smith J, Trower P, Griffin C. What do psychotic experiences mean for young men? A qualitative investigation. Psychol Psychother. 2005 Jun;78(Pt 2):249-70.

70 Larsen JA. Finding meaning in first episode psychosis: experience, agency, and the cultural repertoire. Med Anthropol Q. 2004 Dec; 18(4):447-71.

71 Hanevik H, Hestad KA, Lien L, Joa I, Larsen TK, Danbolt LJ. Religiousness in First-Episode Psychosis. Arch Psychol Relig. 2017 Jul; 39(2):139-64.

72 Hasan AA, Musleh M. Barriers to Seeking Early Psychiatric Treatment amongst Firstepisode Psychosis Patients: A Qualitative Study. Issues Ment Health Nurs. 2017 Aug; 38(8):669-77.

73 Graor CH, Knapik GP. Addressing methodological and ethical challenges of qualitative health research on persons with schizophrenia and bipolar disorder. Arch Psychiatr Nurs. 2013 Apr;27(2):65-71.

74 Breitborde NJ, Srihari VH, Woods SW. Review of the operational definition for first-episode psychosis. Early Interv Psychiatry. 2009 Nov;3(4):259-65.

75 Berkhout SG. Paradigm shift? Purity, progress and the origins of first-episode psychosis. Med Humanit. 2018 Sep;44(3):172-80.
76 National Early Psychosis Project Clinical Guidelines Working Party. Australian Clinical Guidelines for Early Psychosis. Melbourne: National Early Psychosis Project, University of Melbourne, 1998. Melbourne: University of Melbourne; 1998.

77 Tong A, Flemming K, McInnes E, Oliver S, Craig J. Enhancing transparency in reporting the synthesis of qualitative research: ENTREQ. BMC Med Res Methodol. 2012 Nov; 12(1):181.

78 Hacking I. The social construction of what? 8. printing. Cambridge (Mass): Harvard Univ. Press; 2001. p. 261

79 Seikkula J. Psychosis Is Not Illness but a Survival Strategy in Severe Stress: A Proposal for an Addition to a Phenomenological Point of View. Psychopathology. 2019;52(2):143-50.

80 Lachal J, Revah-Levy A, Orri M, Moro MR. Metasynthesis: An Original Method to Synthesize Qualitative Literature in Psychiatry. Front Psychiatry. 2017 Dec;8:269.

81 Bucci S, Berry N, Morris R, Berry K, Haddock G, Lewis S, et al. "They Are Not Hard-toReach Clients. We Have Just Got Hard-toReach Services." Staff Views of Digital Health Tools in Specialist Mental Health Services. Front Psychiatry. 2019 May; 10:344.

82 Moe C, Kvig EI, Brinchmann B, Brinchmann BS. 'Working behind the scenes'. An ethical view of mental health nursing and first-episode psychosis. Nurs Ethics. 2013 Aug;20(5): $517-27$.

83 Odeyemi C, Morrissey J, Donohue G. Factors affecting mental health nurses working with clients with first-episode psychosis: A qualitative study. J Psychiatr Ment Health Nurs. 2018 Sep;25(7):423-31.

84 Camus A. Sur une philosophie del'expression. In: Oeuvres complètes Tome 1. Paris: Gallimard; 1944. p. 908. 